\title{
PROFILE AND MOTIVATION OF WOMEN ENROLLED IN THE BRAZILIAN TELEMEDICINE AND TELEHEALTH POSTGRADUATE DISTANCE EDUCATION PROGRAMME
}

\author{
Alexandra Monteiro MD, PhD, Barbara Grisolia MSc, Juliana Magalhães Aguiar Cardoso, Munique \\ Valério Santos Bara dos Santos
}

Telehealth Centre of Rio de Janeiro State University, Brazil

\begin{abstract}
Purpose: Women's participation in Telehealth is increasing around the world and they should be prepared to work in this new job market. The aim of this study was to evaluate the profile and motivation of women enrolled in the Brazilian Postgraduate Programme on Telemedicine and Telehealth. Methods: A cross-sectional study was conducted from May to July 2018 of all women enrolled in the postgraduate programme using an anonymous online Google form. It consisted of a multiple choice form regarding: age, number of children, profession, date of graduation, current occupation, current number of jobs, workload, postgraduate programmes completed, duration of Telehealth experience and motivation to enrol on the Programme. Data collected were exported to an Excel® sheet, summarised and analysed. Results: Of 44 women, 36 completed the survey. Mean age and time passed since graduation were respectively $43.5 \pm 13.5$ years and $18 \pm 17$ years for student and $53 \pm 13.5$ years and $31.5 \pm 8.5$ for professors; 25 women have at least one child, work more than 30 hours weekly and 10 of them work in two jobs. Health professionals and health occupations were predominant in both groups. Most students had little or no experience in Telehealth. The decreasing order of frequency motivation was professional refinement (63.8\%), job opportunity (55.5\%), financial gain (52.7\%) and innovation (38.8\%). Conclusion: Regardless of age, children, workload and professional qualification, the major women's motivation for enrolling in the Telehealth Postgraduate Programme is to professional refinement in this field.

Keywords: telemedicine; telehealth; women; working; distance education; Brazil

Monteiro A, et al. JISfTeH 2019;7:e3(1-4).

doi: 10.29086/JISfTeH.7.e3

Copyright: ${ }^{\odot}$ The Authors 2018

Open access, published under Creative Commons Attribution 4.0 BY International Licence
\end{abstract}

\section{Introduction}

According to WHO, Telehealth is defined as the use of telecommunication technologies to deliver health care outside of traditional health-care facilities. ${ }^{1}$ One of its applications is the use of information and technologies to provide remote support to deliver health services at distance for the purpose of diagnosis, second opinion, disease monitoring or treatment - telemedicine. Another is related to distance education of healthcare professionals - teleeducation. ${ }^{1}$ Telehealth is expanding globally and people require, training and certification in this area. ${ }^{2}$ There are an increasing number of programmes including undergraduate, ${ }^{3}$ postgraduate $^{4}$ and distance learning courses for upgrading professional qualifications. ${ }^{5-7}$

This new field of virtual heath work requires training and improvement in multidisciplinary areas to work as a part an interdisciplinary virtual team. It requires knowledge in subjects such as bioethics, Internet ethics, telehealth legislation, electronic registration systems, innovation in computer science, privacy, data protection and cyber security, among others. In this sense, educational programmes focused on Telehealth, can contribute by providing professional refinement and knowledge enhancement. ${ }^{3}$

There are over 200 institutions around the world that offer eHealth continuing education and academic postgraduate education programmes, most of which are in Europe and North America. ${ }^{2}$ In Brazil, CAPES (Coordination of Professional Development on Higher Education) is a foundation of the Ministry of Education whose central purpose to approve, coordinate and measure the quality of masters and doctoral courses of Brazilian postgraduate programmes. Currently, CAPES supports a 6,303 postgraduate programmes, 3,398 Academic Masters, 2,202 PhDs and 703 Professional Masters. ${ }^{8}$ In the specific fields of Telemedicine and Telehealth, there are a few Master's or $\mathrm{PhD}$ programmes in the world and in Brazil there is only one - the Brazilian Postgraduate Programme on Telemedicine and Telehealth, a masters level course at distance supported 
by the Telehealth Centre of Rio de Janeiro State University. ${ }^{9}$

The number of women in the labour market is increasing and one of their interests is in the field of the informatics and telehealth. ${ }^{10}$ As an example, in a Latin American Telehealth distance education course, more participants are women and they perform better than men men. ${ }^{11}$ This indicates that women have become aware of telehealth expansion and are seeking to increase their professional qualifications.

Given the above and considering the increase and importance of women in the labour market and in the field of telehealth, the aim of this study was to evaluate the profile, participation and major motivation of women enrolled in the Master's Degree Course of the Brazilian Postgraduate Programme on Telemedicine and Telehealth at distance.

\section{Methods}

A cross-sectional study was performed to evaluate the profile and motivation of women enrolled in the Brazilian Postgraduate Program on Telemedicine and Telehealth Master's Degree. The course was initiated in 2015 and has a teaching workforce of 18 members, 15 of whom are women. At the time of preparation of this paper, the programme had 57 students - including those who concluded or were still attending, 29 of whom were women.

The questionnaire was developed by the authors using a Google form and internal validation was tested for the control group composed of 10 people (five men and five women) of the multidisciplinary team of Rio de Janeiro State University. The women enrolled in the Postgraduate Program and the female professors were invited to participate and the questionnaire was distributed via the Internet between May and July 2018. To proceed with the questionnaire participants had to confirm, by ticking a box, that they had read the summary and objectives of the research, understood that they would not be identifiable and that they consented to participate in the study.

The questionnaire consisted of multiple choice questions regarding: age, number of children, profession, time since graduation, current occupation, current number of jobs, number of hours worked per week, postgraduate programmes completed, duration of practice in the field of telehealth and their motivation to enrol in the Brazilian Telemedicine and Telehealth Postgraduate programme.

The types of professions, occupations and/or postgraduate programmes were grouped as: health (health practitioner, healthcare provider, health postgraduate course), technology (health informatics areas, computer science and engineers) and human sciences (pedagogy, social service, administration and design). In addition, the number of postgraduate programmes completed before enrolling the Telehealth Program and the level of degrees such as Master and/or Doctoral degrees were evaluated. Their current occupation and workload was assessed by considering the number of jobs and number of workload hours per week which was grouped as: 1) up to 20 hours weekly, 2) 20-30 hours weekly, 3) 30-40 hours weekly and 4) more than 40 hours weekly. Telehealth experience was evaluated in years grouped as: 1) up to one year, 2) one to three years, 3) three to five years, 4) five to 10 years and 5) up to 10 years.

The women's motivations to enrol in the Telemedicine and Telehealth Postgraduate programme Master's Degree course were grouped as: new opportunity of job, financial gain, professional refinement and interest in innovation.

\section{Results}

Of the 44 women who were invited to participate, 36 completed the online form $(82 \%)-22$ students and 14 professors. The mean age of students was $43.5 \pm 13.5$ years and of professors was $53 \pm 13.5$ years. Mean time passed since graduation was $18 \pm 17$ years for students and $31.5 \pm 8.5$ years for professors. Eleven students did not have children, eight had one child, two had two children and one had three children. Of the professors, four did not have children; four had one child and six had two children. In total, the majority, 21 have at least one child.

The majority of professors were health professionals 10 (71.4\%) followed by professors of technology related fields $3(21.4 \%)$ and human sciences $1(7.1 \%)$. None of the professors modified the professional area to another area of current occupation. Of the students, 17 (77.3\%) were health professionals - nurses (5), physiotherapist (4), dentists (3), nutritionists (2), and a doctor (1), pharmacist (1) and biologist (1). The five remaining students were from the Human Sciences, in areas such as: social service (1), pedagogy (1), management (1), design (1) and an academic librarian (1). In relation to the current professional occupation comparing with professional graduation completed there was change between the students grouped as Health (14), followed by Human Sciences (6) and Technology (2). In both groups health professionals and health occupations were prevalent between the women enrolled in the Telemedicine and Telehealth Postgraduate Programme.

All professors have Master's and PhD's degrees since it is a requirement to participate as a professor in the Brazilian Telemedicine and Telehealth Postgraduate Programme. The health professionals, including the professors and the students, have at least one specialisation in their health areas. One health professional student had concluded her specialisation, Master and $\mathrm{PhD}$ degrees in health areas before enrolling in the Program. Two students of technology areas had concluded one specialisation in their specific areas.

Ten women health professionals (6 students and 4 professors) work in two jobs per week. Thirteen women (4 students and 9 professors) work 40 hours per week, 16 (11 students and 5 professors) work 30-40 hours weekly, 2 students work 30-20 hours weekly and 5 students up to 20 hours weekly. The workload per week did not seem to 
interfere with the motivation for professional qualification to work in Telehealth.

Eight of 22 students reported no prior activity in the telehealth field; 3 reported up to 1 year, 5 (1 to 3 years), 4 (3 to 5 years), 1 (5 to 10 years) and 1 reported more than 10 years' experience. Of the 14 professors: 1 reported 1 to 3 years, 6 ( 3 to 5 years), 4 ( 5 to 10 years) and 3 reported more than 10 years' experience. The majority of the students did had little or no experience in telehealth.

Major motivations to enrol in the programme were professional refinement (23) followed by new job opportunity (20), financial gain (19) and interest in innovation (14). Most of the participants chose more than one option in the online form. Only the students' group choose one option: two students from technology areas reported interest in innovation and three students from health areas in professional refinement. None of the professors chose interest in innovation as their reason for motivation in this field. Results are shown in Table 1.

\section{Discussion}

This cross-sectional study was conducted to explore the profile and motivation of Brazilian women enrolled in the Master's Degree Course of the Brazilian Postgraduate Programme on Telemedicine and Telehealth at distance. Most participants were middle aged, working in healthcare with at least one specialisation for the majority of the students. All professors had a Master and PhD degree. Mean workload was more than 30 hours a week and most had at least one child. Telehealth, experience was limited and major motivations to participate were professional refinement and new job opportunity.

As far as we know, no similar study has been published before providing information relating only to profiles and motivations of women participating in a Telemedicine and/or a Telehealth Postgraduate Programme. Telehealth is a notable growth area, as can be seen by the increase in the number of general postgraduate programmes in Telehealth globally, ${ }^{2}$ and in the increasing number of women in the field of informatics and telehealth. ${ }^{10}$

Women are increasing their participation in different fields of specialisation. The number of women participating in the overall labour market has grown from $18 \%$ to $27 \%$ in the $20^{\text {th }}$ century and, in health area, female participation is approximately $70 \%$, with $62 \%$ in senior positions. ${ }^{12}$ In addition, $33.5 \%$ of Brazilians workers in the health area are women $^{12}$ and they represent the majority in many postgraduate programmes as presented by CAPES in 2015, of the 325,655 post-graduation students, 175,419 are women $(54 \%){ }^{8}$ Our findings show that women outnumber men on the Master's Degree Course of the Brazilian Postgraduate Programme on Telemedicine and Telehealth. However, Telehealth mainly remains an area with an insufficient number of women enrolled as health professionals, leaders, IT designers. ${ }^{13}$

To climb the professional ladder, women have had to work hard in their jobs as well as managing their personal life and caring for their children. In a study about women's career choices in radiology in France, 74\% of women stated 'yes' or 'probably' that maternity might influence in their career choices. ${ }^{14}$ Twenty-one $(58.4 \%)$ of our sample had children but neither 'number of children', nor 'time since graduation', or 'post-graduation programmes' previously completed had an impact on the decision to enrol in the Telehealth Postgraduate Programme.

Within the work force, working hours have constantly increased since 1990. ${ }^{14}$ A Spanish study about women's quality of life found that $38 \%$ felt that they worked too much. It was also noted that they have to do more than one task at a time to increase their free time. ${ }^{15}$ Twenty-nine participants in our study work more than 30 hours a week, 10 of them work in two jobs and in spite of this 20 of them were taking the course to open new job opportunities and 19 because they seek financial gain from the completing course.

Having a postgraduate qualification is an important factor and improve professional status. ${ }^{4}$ In our study, all professors have a $\mathrm{PhD}$ degree and most of the students have completed

Table 1. Women's reasons to participate in the Telemedicine and Telehealth Postgraduate Programme.

\begin{tabular}{|c|c|c|c|c|c|}
\hline & $\mathbf{n}=$ & $\begin{array}{l}\text { Professional } \\
\text { refinement }\end{array}$ & $\begin{array}{c}\text { New job } \\
\text { opportunity }\end{array}$ & Financial gain & Innovation \\
\hline \multirow[t]{9}{*}{ Students } & 1 & $\mathrm{x}$ & $\mathrm{x}$ & $\mathrm{x}$ & $\mathrm{x}$ \\
\hline & 1 & $\mathrm{x}$ & $\mathrm{x}$ & $\mathrm{x}$ & \\
\hline & 1 & & $\mathrm{x}$ & $\mathrm{x}$ & $\mathrm{x}$ \\
\hline & 4 & $\mathrm{x}$ & $\mathrm{x}$ & & $\mathrm{x}$ \\
\hline & 6 & & $\mathrm{x}$ & & $\mathrm{x}$ \\
\hline & 2 & & $\mathrm{x}$ & & \\
\hline & 3 & $\mathrm{x}$ & & & \\
\hline & 2 & & & $\mathrm{x}$ & \\
\hline & 2 & & & & $\mathrm{x}$ \\
\hline \multirow[t]{2}{*}{ Professors } & 9 & $\mathrm{x}$ & & $\mathrm{x}$ & \\
\hline & 5 & $\mathrm{x}$ & $\mathrm{x}$ & $\mathrm{x}$ & \\
\hline Total & 36 & $23(63.9 \%)$ & $20(55.6 \%)$ & $19(52.8 \%)$ & $14(38.9 \%)$ \\
\hline
\end{tabular}


at least one specialisation but despite this, 23 were motivated to take the course for professional refinement.

In spite of the small sample size in this study, it portrays the motivation of women who sought the specific professional refinement in the field of Telehealth through a Postgraduate Programme in Brazil. The Masters course began 3 years ago, and of all the women participants we had a response rate of $81.8 \%(n=36)$. It is recommended that other studies should be performed with the same aims to identify and investigate profile and preferences of women for telehealth related to labour market issues worldwide, so results can be evaluate on a larger scale.

\section{Conclusion}

Regardless of personal life, career and workload, women who enrolled in the programme were in search of professional refinement, new opportunities for professional qualification, opportunity for new jobs and positions in the labour market and, therefore, greater financial gain. This new field of virtual work may be a strategy to deal with balancing working hours and personal life.

\section{Corresponding author:}

Alexandra Monteiro

Telehealth Center. Rio de Janeiro State University (UERJ

Hospital Universitário Pedro Ernesto

Av.Vinte e Oito de Setembro,77.Térreo.Sala 126

Vila Isabel.Rio de Janeiro.RJ.Brasil.CEP:20551-030

eMail: coordenacao@telessaude.uerj.br

Conflict of interest. The authors declare no conflicts of interest.

\section{References}

1. World Health Organization (WHO) (2018).

Telehealth. Available at:

http://www.who.int/sustainable-development/healthsector/strategies/telehealth/en/ accessed 26 June 2018.

2. Herzog J, Pohn B, Forjan M, et al. Education for eHealth - a status analysis. Stud Health Technol Inform 2014;198:172-179. Doi: 10.3233/978-1-61499397-1-172

3. Santos, SCF, AS Pecanha, Monteiro AM, et al. Telemedicine as a support for the discipline of radiology from the faculty of medical sciences. Global Telemed eHealth Updates: Knowl Resourc 2014;7:353-354.

4. Urbauer P, Herzog J, Pohn B, et al. Certification programmes for eHealth - status quo. Stud Health Technol Inform 2014;198:164-171. Doi: 10.3233/9781-61499-397-1-164
5. Baesse DCEL, Oliveira, AEF, Monteiro AMG.

Pedagogical monitoring as a tool to reduce dropout in distance learning in family health. BMC Med Educ 2016;16:213. https://doi.org/10.1186/s12909-0160735-9

6. Rendeiro, MMP, Monteiro AMG. Learning opportunities: teledentistry contributions to continuing education in Brazil. Global Telemed eHealth Updates: Knowl Resourc 2014;7:330-333.

7. Rocha M, Santos M, Santos R, et al. Telehealth Brazil Networks Programme RJ-UERJ Nucleus: Telehealth as a means to professional update in primary health. Global Telemed eHealth Updates: Knowl Resourc 2014;7:341-343.

8. Avaliação da CAPES aponta crescimento da pósgraduação Brasileira. Available at:

http://www.capes.gov.br/sala-deimprensa/noticias/8558-avaliacao-da-capes-apontacrescimento-da-pos-graduacao-brasileira accessed 12 August 2018.

9. Telessaúde UERJ. Mestrado Profissional em Telemedicina e Telessaúde. Available at: http://www.telessaude.uerj.br/mestrado/ accessed 12 June 2018.

10. Banerjee R, George P, Priebe C, et al. Medical student awareness of and interest in clinical informatics. $J \mathrm{Am}$ Med Inform Assoc 2015;22(1):42-47. https://doi.org/10.1093/jamia/ocu046

11. Santos AD, Alves HJ, Nogueira JT, Torres RM, Melo MD. Telehealth distance education course in Latin America: analysis of an experience involving 15 countries. Telemed J E Health 2014;20(8):736-741. https://doi.org/10.1089/tmj.2013.0291

12. Workforce at the Health Sector in Brazil: Focusing on Feminization. (2010). Revista Divulgação em Saúde para Debate. Available at:

http://www.ensp.fiocruz.br/observarh/arquivos/A\%20 Forca\%20de\%20Trabalho\%20do\%20Setor\%20de\%20 Saude\%20no\%20Brasil\%20.pdf accessed 25 July 2018.

13. Thouvenot VI, Holmes K. Women and eHealth 20102015: From the study to the Women observatory for eHealth. J Int Soc Telemed eHealth 2015;3(7):1-6.

14. Pyatigorskaya N, Madson M, Di Marco L. Women's career choices in radiology in France. Diagn Interv Imaging 2017;98(11):775-783. https://doi.org/10.1016/j.diii.2017.06.017

15. Boixados M, Hernandez E, Guillamon N, et al. Working women's lifestyles and quality of life in the information society. Health Care Women Int 2010;31(6):552-567. https://doi.org/10.1080/07399331003721365 